\title{
NUTRIÇÃO MINERAL DE SERINGUEIRA. XII. ABSORÇÃO DE MACRO E MICRONUTRIENTES NOS PRIMEIROS 240 DIAS
}

\author{
I.de J.M. VIÉGAS ${ }^{1}$; H.P. HAAG ${ }^{2}$; N. BUENO³ ; J.da P. PEREIRA ${ }^{4}$
}

\begin{abstract}
RESUMO: Com o objetivo de obter informações referentes ao crescimento, concentração e conteúdo de macronutrientes e micronutrientes em plantas de seringueira, foram coletadas amostras de folhas, caule e raízes aos $60,120,180$ e 240 dias de idade em condições de casa de vegetação. Os resultados obtidos mostraram que: o maior incremento do crescimento ocorreu a partir dos 180 dias; as maiores concentrações de nutrientes exceto para o ferro ocorreram nas folhas; a extraçāo de nutrientes por hectare, nos 240 dias foi o seguinte: $N=60,0 \mathrm{~kg}$, $P=12 \mathrm{~kg}, \mathrm{~K}=27,74 \mathrm{~kg}, \mathrm{Ca}=8,97 \mathrm{~kg}, \mathrm{Mg}=5,32 \mathrm{~kg}, \mathrm{~S}=6,21 \mathrm{~kg}, \mathrm{~B}=45,52 \mathrm{~g}, \mathrm{Fe}=544 \mathrm{~g}, \mathrm{Mn}=337,74 \mathrm{~g} \mathrm{e}$ $\mathrm{Zn}=77,30 \mathrm{~g}$.
\end{abstract}

Descritores: seringueira, nutrição mineral, macronutrientes, micronutrientes.

\section{NUTRIENT ABSORPTION IN THE FIRST 240 DAYS OF GROWTH OF Hevea spp}

ABSTRACT: Rubber plants were grown in a greenhouse and sampled at 60, 120, 180 and 240 days of growth. Samples were separated in leaves, stems and roots. Growth rate and nutrients concentrations were analyzed. The highest growth rate was obtained after 180 days of plant growth.Except for iron, the highest nutrient concentrations were determined in the leaves. Nutrient extractions per hectare at the 240 day were: $N=60 \mathrm{~kg}$; $\mathrm{P}=12 \mathrm{~kg} ; \mathrm{K}=27,74 \mathrm{~kg} ; \mathrm{Ca}=8,97 \mathrm{~kg} ; \mathrm{Mg}=5,32 \mathrm{~kg} ; \mathrm{S}=6,21 \mathrm{~kg} ; \mathrm{B}=45,52 \mathrm{~g} ; \mathrm{Fe}=544 \mathrm{~g} ; \mathrm{Mn}=337,74 \mathrm{~g}$ and $\mathrm{Zn}=\mathbf{7 7 , 3 0 g}$.

Key Words: Hevea, mineral nutrition, macronutrients, micronutrients.

\section{INTRODUÇÃo}

Tendo em vista a crescente expansão da heveicultura no Estado de São Paulo, que possue atualmente cerca de 25.000 ha, torna-se necessário gerar tecnologias compatíveis com as condições deste Estado. Deste modo, há necessidade de desenvolver trabalhos de pesquisa, com a finalidade de solucionar problemas relacionados principalmente à produtividade e manejo da seringueira.

O conhecimento do estado nutricional da seringueira é um requisito básico para uma recomendação mais adequada de fertilizantes, visando alcançar uma maior produtividade.

$\mathrm{Na}$ cultura da seringueira, os estudos sobre nutrição não tem merecido a devida atenção no Brasil. Entretanto, nos últimos anos houve uma pequena melhoria, devida ao desenvolvimento desta cultura e à publicação de alguns trabalhos nesta área (AMARAL,
1983; GUERRINI, 1983; HAAG et al., 1986; BUENO, 1987; BATAGLIA \& CARDOSO, 1987; PEREIRA, 1989; MARQUES, 1990). Há porém a necessidade de incrementar estudos de nutrição mineral de seringal em desenvolvimento e produção. O presente trabalho foi realizado com os seguintes objetivos: 1. analisar o crescimento da planta através da altura, diâmetro do caule e produção de matéria seca. 2 . determinar a concentração e o acúmulo de macronutrientes e micronutrientes nas diversas partes da planta em função da idade.

\section{MATERIAL E MÉTODOS}

O experimento foi conduzido em casa de vegetação do Departamento de Química da Escola Superior de Agricultura "Luiz de Queiroz", USP, em Piracicaba-SP.

\footnotetext{
I Pesquisador EMBRAPA/CPATU, Belém,PA.

${ }^{2}$ Professor Titular, ESALQ/USP, Departamento de Química, Piracicaba,SP.

${ }^{3}$ Pesquisador EMBRAPA/CPAA, Manaus,AM.

${ }^{4}$ Pesquisador EMBRAPA/SEDE, Brasilia, DF.
} 
Foram utilizadas sementes clonais ilegítimas de seringueira (Hevea spp), procedentes de uma plantação comercial no município de Paloni, planalto paulista.

As sementes foram postas para germinar $\mathrm{em}$ caixas de madeira com $20 \mathrm{~cm}$ de profundidade contendo como substrato vermiculita. A germinação ocorreu no início do décimo dia após a semeadura. Quando as plantas apresentaram o primeiro fluxo de folhas com gema apical em dormência, (cêrca de quarenta e cinco dias apos a semeadura), foram selecionadas e transplantadas em números de duas para cada recipiente, sendo antes lavadas as raízes com jatos de água de tomeira e posteriormente em água desmineralizada para completa limpeza.

Os recipientes utilizados foram vasos de plástico com capacidade para 4 litros com solução nutritiva segundo BOLLE-JONES (1957). A solução nutritiva foi renovada a intervalos de 15 dias.

$O$ delineamento experimental foi inteiramente casualizado com 4 repetições e 4 tratamentos.

Aos 60, 120, 180 e 240 dias após a instalação, as plantas foram coletadas separadas em folhas, caules e raízes. $O$ material colhido foi lavado inicialmente em água de torneira e em seguida com água desmineralizada.

0 material colhido nas diferentes partes de cada planta, foi acondicionado em saco de papel e colocado em estufa com circulação forçada de ar, temperatura 70-750C, até atingir peso constante. Após a determinação do peso da materia seca, procedeu-se a moagem do material visando determinação química de $\mathrm{N}, \mathrm{P}, \mathrm{K}, \mathrm{Ca}, \mathrm{Mg}, \mathrm{S}, \mathrm{Fe}, \mathrm{Mn}, \mathrm{Zn}$ e $\mathrm{B}$ segundo metodologia descrita por SARRUGE e HAAG (1974).

As variáveis utilizadas para avaliar os efeitos dos tratamentos foram altura das plantas, diâmetro do caule a $5 \mathrm{~cm}$ do coleto, produção de matéria seca, concentração e acúmulo de macro e micronutrientes nos vários 6rgãos da planta.

\section{RESULTADOS E DISCUSSÃO}

Os resultados mostrando o efeito dos tratamentos sobre altura das plantas, diâmetro do caule e produção da matéria seca, estão contidos na Tabela 1. Verifica-se que as plantas cresceram linearmente em altura e diâmetro no decorrer da idade, como era esperado, atingindo aos 240 dias, $98 \mathrm{~cm}$ e $0,72 \mathrm{~cm}$ respectivamente, sendo que o maior incremento ocorreu entre 180 a 240 dias após o plantio. $O$ peso da matéria seca para folha e caule até aos 180 dias, não apresentou incremento significativo, apesar de duplicar a cada 60 dias. Em todas as partes da planta o maior incremento de matéria seca ocorreu entre 180 e 240 dias.

A Figura 1, ilustra o comportamento dos diversos órgãos das plantas em função da produção da matéria seca, mostrando um crescimento linear com a idade, sendo obedecida a seguinte ordem: Folha > Caule > Raiz.

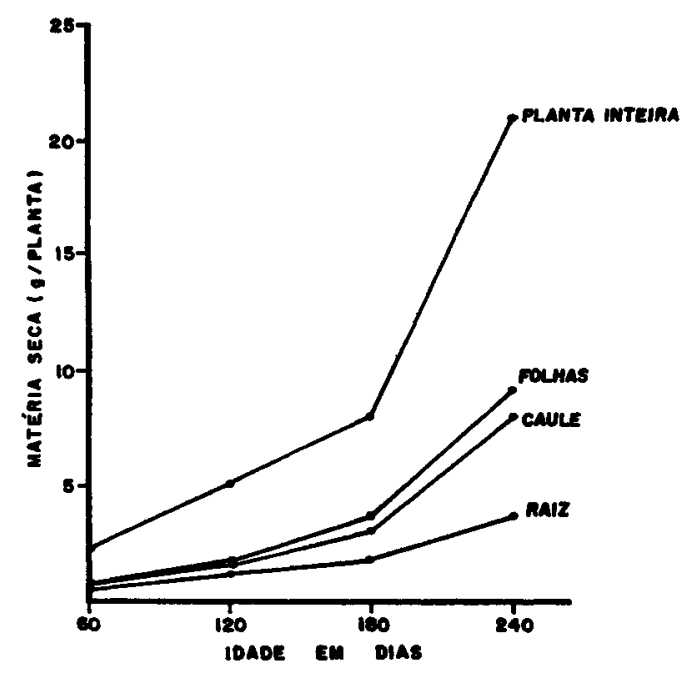

Figura 1 - Produção de matéria seca em diversos órgãos da seringueira em função da idade.

Os resultados da concentração dos macronutrientes nas folhas, caule e raízes das plantas de seringueira em função da idade encontram-se na Tabela 2. Percebe-se que não ocorreu variação significativa na concentração foliar do nitrogênio e potássio. GUERRINI (1983), também não encontrou variação na concentração foliar do nitrogênio e potássio nos três primeiros anos em seringal em desenvolvimento. Por outro lado, houve variação para o fósforo, cálcio, magnésio e enxofre. As variações na concentração mostraram que o nitrogênio e cálcio apresentaram teores mais altos nas folhas, enquanto o fósforo, potássio e magnésio nas raízes (Tabela 3).

Guardadas as devidas proporções, as concentrações foliares do presente trabalho são as obtidas por VIÉGAS (1985), assim como, com as obtidas por AMARAL (1983), com relação 20 nitrogênio e por BUENO (1987) para o magnésio e enxofre. As variações nas concentrações das raízes, mostraram que os teores mais altos foram de fósforo e potássio, sendo superiores aos obtidos nas folhas e caule (Tabela 3).

Os resultados das concentrações dos 


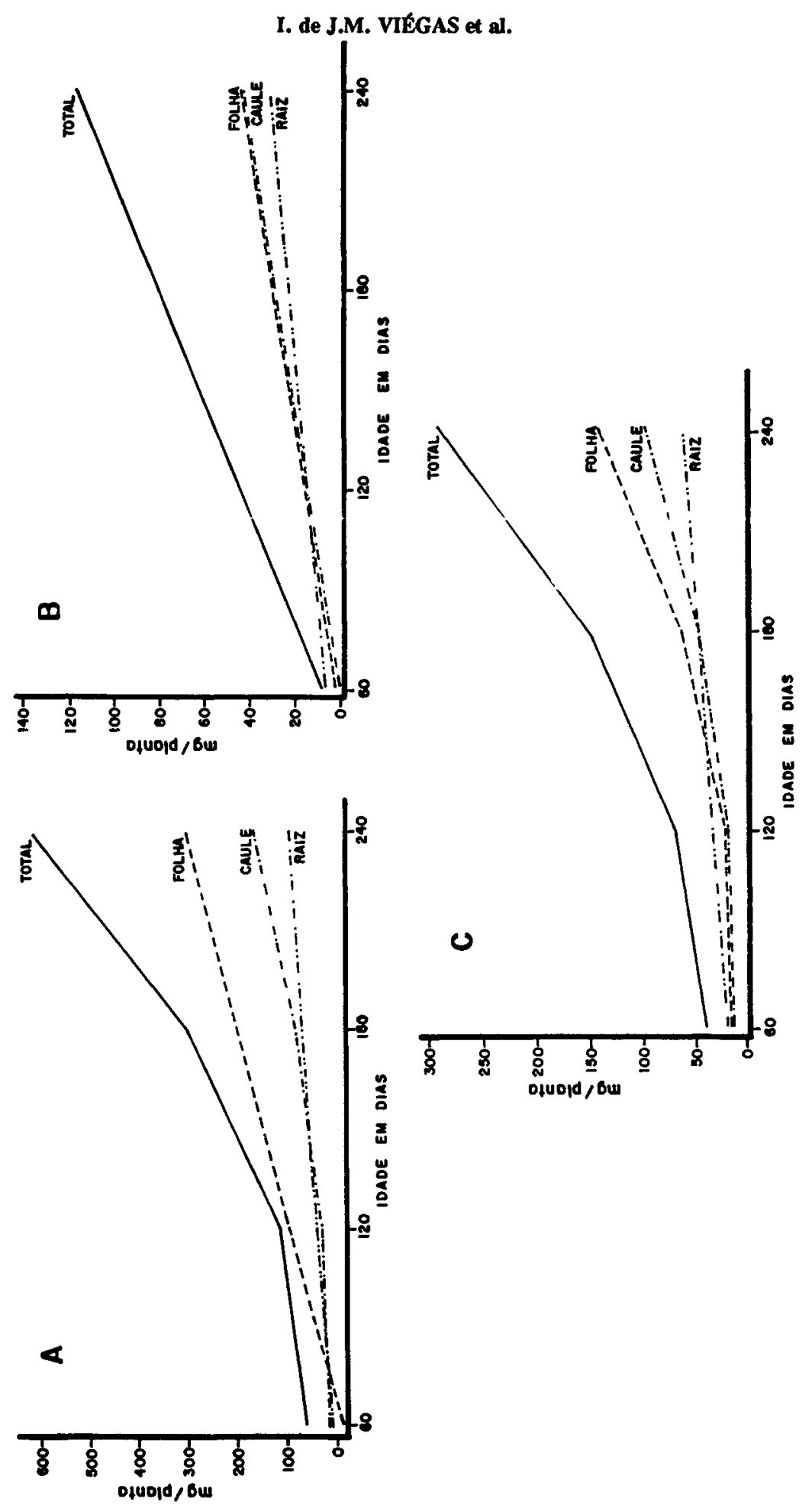

Figura 2 - Acúmulo de nitrogênio (A), fósforo (B) e potássio (C) nas folhas, caule, rázes e total na seringueira, em função da idade. 

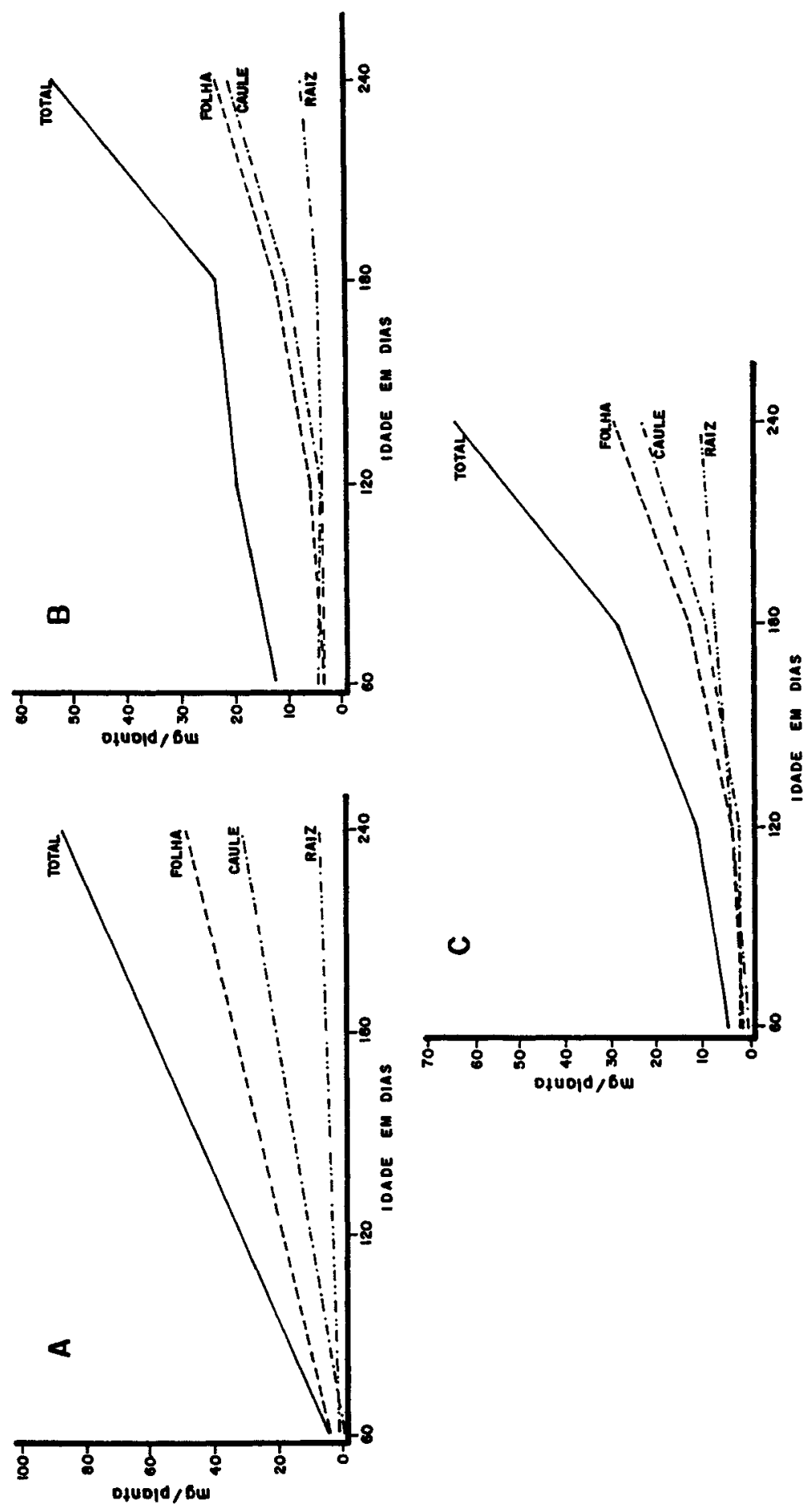

Figura 3 - Acúmulo de cálcio (A), magnésio (B) e enxofre (C) nas folhas, caule, raízes e total na seringueira, em função da idade. 
Tabela 1 - Crescimento de plantas de seringueira em função da idade.

\begin{tabular}{||ccccccc||}
\hline \multirow{2}{*}{$\begin{array}{r}\text { Idade } \\
\text { (dias) }\end{array}$} & \multirow{2}{*}{ Altura } & Diâmetro & \multicolumn{4}{c|}{ Peso da matéria seca (g/planta) } \\
\cline { 5 - 7 } & $(\mathrm{cm})$ & $(\mathrm{cm})$ & Folha & Caule & Raíz & Total \\
60 & $28.15 \mathrm{c}$ & $0.35 \mathrm{~d}$ & $0.85 \mathrm{~b}$ & $0.80 \mathrm{~b}$ & $0.70 \mathrm{c}$ & $2.35 \mathrm{c}$ \\
120 & $52,15 \mathrm{~b}$ & $0.44 \mathrm{c}$ & $1.87 \mathrm{~b}$ & $1.85 \mathrm{~b}$ & $1.30 \mathrm{bc}$ & $5.02 \mathrm{bc}$ \\
180 & $61.52 \mathrm{~b}$ & $0.56 \mathrm{~b}$ & $3.92 \mathrm{~b}$ & $3.99 \mathrm{~b}$ & $1.87 \mathrm{~b}$ & $8.79 \mathrm{~b}$ \\
240 & $97.72 \mathrm{a}$ & $0.72 \mathrm{a}$ & $9.25 \mathrm{a}$ & $8.02 \mathrm{a}$ & $3.82 \mathrm{a}$ & $21.09 \mathrm{a}$ \\
\hline
\end{tabular}

Valores com letras iguais na mesma coluna, não diferem entre si ao nível de $5 \%$ de probabilidade pelo Teste de Tukey.

Tabela 2 - Concentração de macronutrientes nas folhas, caule e raízes de seringueira em função da idade.

\begin{tabular}{|c|c|c|c|c|c|c|}
\hline Idade & $\mathrm{N}$ & $P$ & $\mathrm{~K}$ & $\mathrm{Ca}$ & $\mathrm{Mg}$ & $S$ \\
\hline (dias) & \multicolumn{6}{|c|}{$\%$} \\
\hline & \multicolumn{6}{|c|}{ FOLHAS } \\
\hline 60 & $2.63 \mathrm{a}$ & $0.28 c$ & $1.22 \mathrm{a}$ & $0.56 \mathrm{c}$ & $0.33 b$ & $0.11 \mathrm{~b}$ \\
\hline 120 & $3.61 \mathrm{a}$ & $0.88 \mathrm{a}$ & $1.35 \mathrm{a}$ & $0.97 \mathrm{a}$ & $0.45 \mathrm{a}$ & $0.29 \mathrm{a}$ \\
\hline 180 & $3.49 \mathrm{a}$ & $0.64 \mathrm{ab}$ & $1.39 \mathrm{a}$ & $0.76 b$ & $0.27 \mathrm{~b}$ & $0.28 \mathrm{a}$ \\
\hline \multirow[t]{2}{*}{240} & $3.78 \mathrm{a}$ & $0.50 \mathrm{bc}$ & $1.51 \mathrm{a}$ & $0.53 \mathrm{c}$ & $0.27 \mathrm{~b}$ & $0.32 \mathrm{a}$ \\
\hline & \multicolumn{6}{|c|}{ CAULE } \\
\hline 60 & $1.30 \mathrm{~b}$ & $0.41 \mathrm{~b}$ & $1.28 \mathrm{a}$ & $0.30 \mathrm{a}$ & $0.37 \mathrm{a}$ & $0.18 \mathrm{a}$ \\
\hline 120 & $2.43 a$ & $0.77 \mathrm{a}$ & $1,10 \mathrm{a}$ & $0.41 \mathrm{a}$ & $0.38 \mathrm{a}$ & $0.22 \mathrm{a}$ \\
\hline 180 & $2.31 \mathrm{a}$ & $0.59 \mathrm{ab}$ & $1.32 \mathrm{a}$ & $0.47 \mathrm{a}$ & $0.27 \mathrm{a}$ & $0.27 \mathrm{a}$ \\
\hline \multirow[t]{2}{*}{240} & $2.28 \mathrm{a}$ & $0.63 \mathrm{ab}$ & $1.19 \mathrm{a}$ & $0.44 \mathrm{a}$ & $0.29 \mathrm{a}$ & $0.30 \mathrm{a}$ \\
\hline & \multicolumn{6}{|c|}{ RAIIZES } \\
\hline 60 & $2.09 \mathrm{a}$ & $0.80 \mathrm{~b}$ & $2.22 \mathrm{a}$ & $0.28 \mathrm{a}$ & $0.68 \mathrm{a}$ & $0.13 b$ \\
\hline 120 & $2.76 a$ & $1.32 \mathrm{a}$ & $2.31 \mathrm{a}$ & $0.23 \mathrm{a}$ & $0.38 \mathrm{~b}$ & $0.28 \mathrm{a}$ \\
\hline 180 & $2.79 \mathrm{a}$ & $1.21 \mathrm{ab}$ & $2.50 \mathrm{a}$ & $0.25 \mathrm{a}$ & $0.24 b c$ & $0.30 \mathrm{a}$ \\
\hline 240 & $2.74 a$ & $0.78 \mathrm{~b}$ & $1.47 \mathrm{~b}$ & $0.22 \mathrm{a}$ & $0.22 c$ & $0.31 a$ \\
\hline
\end{tabular}


Tabela 3 - Variações na concentração das folhas, caule e raizes de madronutrientes em plantas de seringueira.

\begin{tabular}{|cccc|}
\hline MACRONUTRIENTES (\%) & Folhas & Caule & Raizes \\
\cline { 2 - 4 } N & $2,63-3,78$ & $1,30-2,43$ & $2,09-2,79$ \\
P & $0,28-0.88$ & $0,41-0,77$ & $0,78-1,32$ \\
K & $1,22-1,51$ & $1,10-1,32$ & $1,47-2,50$ \\
Ca & $0,53-0,97$ & $0,30-0,47$ & $0,22-0,28$ \\
Mg & $0,27-0,45$ & $0,27-0,38$ & $0,22-0,68$ \\
S & $0,11-0,32$ & $0,18-0,30$ & $0,13-0,31$ \\
\hline
\end{tabular}

Tabela 4 - Concentração de micronutrientes nas folhas, caule e raízes de seringueira em função da idade.

\begin{tabular}{|c|c|c|c|c|}
\hline Idade & B & $\mathrm{Fe}$ & Mn & $\mathrm{Zn}$ \\
\hline (dias) & \multicolumn{4}{|c|}{ ppm } \\
\hline & \multicolumn{4}{|c|}{ FOLHAS } \\
\hline 60 & $50.00 \mathrm{~b}$ & $134.25 b$ & $59.25 c$ & $36.0 \mathrm{a}$ \\
\hline 120 & $132.50 \mathrm{a}$ & $227.25 \mathrm{a}$ & $284.75 a$ & $25.25 \mathrm{a}$ \\
\hline 180 & $109.75 \mathrm{a}$ & $91.50 \mathrm{~b}$ & $186.75 \mathrm{~b}$ & $23.00 \mathrm{a}$ \\
\hline \multirow[t]{2}{*}{240} & $35.50 \mathrm{~b}$ & $79.00 \mathrm{~b}$ & $176.50 \mathrm{~b}$ & $36.25 \mathrm{a}$ \\
\hline & \multicolumn{4}{|c|}{ CAULE } \\
\hline 60 & $21.00 \mathrm{a}$ & $74.25 \mathrm{a}$ & $39.75 b$ & $23.25 \mathrm{ab}$ \\
\hline 120 & $21.25 \mathrm{a}$ & $60.75 a$ & $85.50 \mathrm{a}$ & $18.25 b$ \\
\hline 180 & $17.50 \mathrm{a}$ & $39.25 \mathrm{a}$ & $73.50 \mathrm{ab}$ & $25,75 \mathrm{ab}$ \\
\hline \multirow[t]{2}{*}{240} & $11.50 \mathrm{a}$ & $43.75 a$ & $81.25 a b$ & $31.00 \mathrm{a}$ \\
\hline & \multicolumn{4}{|c|}{ RAIZES } \\
\hline 60 & $27.25 \mathrm{a}$ & $1674.75 \mathrm{a}$ & $384.75 \mathrm{a}$ & $30.00 \mathrm{~b}$ \\
\hline 120 & $22.50 \mathrm{a}$ & $929.50 \mathrm{~b}$ & $392.75 \mathrm{a}$ & $31.25 \mathrm{~b}$ \\
\hline 180 & $21.75 \mathrm{a}$ & $684.75 b$ & $289.75 \mathrm{a}$ & $36.00 \mathrm{ab}$ \\
\hline 240 & $20.75 a$ & $1214,25 \mathrm{ab}$ & $310.25 \mathrm{a}$ & $68.25 \mathrm{a}$ \\
\hline
\end{tabular}


Tabela 5 - Variações na concentração das folhas, caule e raízes de micronutrientes em plantas de seringueira.

\begin{tabular}{||cccc|}
\hline MICRONUTRIENTES (ppm) & Folhas & Caule & Raízes \\
\cline { 2 - 4 } B & $35.50-132.50$ & $11.50-21.25$ & $20.75-27.25$ \\
Fe & $79.0-227.25$ & $39.25-74.25$ & $684.75-1674.75$ \\
Mn & $59.25-284.75$ & $39.75-85.50$ & $310.25-392.75$ \\
Zn & $23.00-36.25$ & $18.25-31.00$ & $30.00-68.25$ \\
\hline
\end{tabular}

Tabela 6 - Conteúdo total de macronutrientes em plantas de seringueira.

\begin{tabular}{||ccc||}
\hline Nutrientes (mg/planta) & Alvim \& Machado, 1972 & Presente Trabalho \\
N & 75 & 148 \\
P & 70 & 76 \\
K & 36 & 47 \\
Ca & 30 & 29 \\
Mg & 18 & 18 \\
S & 11 & 13 \\
\hline
\end{tabular}

Tabela 7 - Quntidades de nutrientes contidos em $95.000^{1}$ plantas por hectare.

\begin{tabular}{||cccccc||}
\hline & & \multicolumn{5}{c||}{ Idade (dias) } \\
\cline { 3 - 6 } Nutrientes & Unidade & 60 & 120 & 180 & 240 \\
\hline $\mathrm{N}$ & $\mathrm{kg}$ & 4.51 & 14.10 & 24.98 & 60.00 \\
$\mathrm{P}$ & $\mathrm{kg}$ & 1.04 & 4.48 & 6.12 & 12.00 \\
$\mathrm{~K}$ & $\mathrm{~kg}$ & 3.37 & 7.24 & 13.39 & 27.74 \\
$\mathrm{Ca}$ & $\mathrm{kg}$ & 0.85 & 2.77 & 4.72 & 8.97 \\
$\mathrm{Mg}$ & $\mathrm{kg}$ & 0.99 & 1.75 & 2.23 & 5.32 \\
$\mathrm{~S}$ & $\mathrm{~kg}$ & 0.33 & 1.26 & 2.87 & 6.21 \\
& & & & & \\
$\mathrm{~B}$ & $\mathrm{~g}$ & 7.50 & 29.99 & 50.23 & 45.52 \\
$\mathrm{Fe}$ & $\mathrm{g}$ & 127,89 & 165.75 & 168.07 & 544.08 \\
Mn & $\mathrm{g}$ & 33.17 & 114.49 & 143.02 & 337.74 \\
$\mathrm{Zn}$ & $\mathrm{g}$ & 6.62 & 11.59 & 21.94 & 77.30 \\
\hline Total & $\mathrm{kg}$ & 11.26 & 31.92 & 54.69 & 121.24 \\
\hline Peso de Matéria Seca & $\mathrm{kg}$ & 223,2 & 476.9 & 836.0 & 2004.5 \\
\hline Nutrientes eem relação & & & & 6.6 & 6.0 \\
à matéria seca & $\%$ & 5.0 & 6.5 & 6 \\
\hline
\end{tabular}

1 = Espaçamento de $0,60 \mathrm{~m} \times 0,15 \mathrm{~m}$, em fileiras sextuplas distanciadas de $1,20 \mathrm{~m}$. 
Tabela 8 - Acréscimos percentuais da absorção de nutrientes em função da idade.

\begin{tabular}{||ccccc||}
\hline \multirow{2}{*}{ Nutrientes } & \multicolumn{3}{c|}{ Idade (dias) } \\
\cline { 2 - 5 } & 60 & 120 & 180 & 240 \\
\hline $\mathrm{N}$ & 100 & 312 & 554 & 1330 \\
$\mathrm{P}$ & 100 & 430 & 588 & 1154 \\
$\mathrm{~K}$ & 100 & 215 & 397 & 823 \\
$\mathrm{Ca}$ & 100 & 326 & 555 & 1055 \\
$\mathrm{Mg}$ & 100 & 177 & 555 & 1055 \\
$\mathrm{~S}$ & 100 & 382 & 870 & 1882 \\
$\mathrm{~B}$ & 100 & 400 & 670 & 607 \\
$\mathrm{Fe}$ & 100 & 130 & 131 & 425 \\
$\mathrm{Mn}$ & 100 & 345 & 431 & 1018 \\
$\mathrm{Zn}$ & 100 & 175 & 331 & 1168 \\
\hline
\end{tabular}

Tabela 9 - Equações de regressão e coeficientes de determinação do acúmulo de macronutrientes e micronutrientes na planta (raíz + caule + folhas).

\begin{tabular}{||c|cc||}
\hline Nutrientes & Equações & \multicolumn{1}{c||}{$\mathrm{R}^{2}$} \\
\hline $\mathrm{N}$ & $\mathrm{y}=-194,0000+3,10416 \mathrm{x}$ & $88,92^{* *}$ \\
$\mathrm{P}$ & $\mathrm{y}=-28,62500+0,60625 \mathrm{x}$ & $94,72^{* *}$ \\
$\mathrm{~K}$ & $\mathrm{y}=-72,37500+1,39041 \mathrm{x}$ & $91,50^{* *}$ \\
$\mathrm{Ca}$ & $\mathrm{y}=-23,62500+0,46166 \mathrm{x}$ & $95,55 * *$ \\
$\mathrm{Mg}$ & $\mathrm{y}=-7,12500+0,23208 \mathrm{x}$ & $83,39 * *$ \\
$\mathrm{~S}$ & $\mathrm{y}=-22,87500+0,33166 \mathrm{x}$ & $88,49 * *$ \\
& & \\
$\mathrm{~B}$ & $\mathrm{y}=-2,75000+2,35625 \mathrm{x}$ & $81,07 * *$ \\
$\mathrm{Fe}$ & $\mathrm{y}=3804,37500-52,20208 \mathrm{x}$ & $92,70^{* *}$ \\
$\mathrm{Mn}$ & $\mathrm{y}=-838,25000+16,57208 \mathrm{x}$ & $88,86 * *$ \\
$\mathrm{Zn}$ & $\mathrm{y}=-276,12500+3,90583 \mathrm{x}$ & $77,86 * *$ \\
\hline
\end{tabular}


micronutrientes nas folhas, caule e raízes das plantas de seringueira em funçâo da idade estão inseridas na Tabela 4. Houve variação nas concentrações foliares para boro, ferro e manganês. No caule, só ocorreu variação nos teores de manganês e zinco. Nas raízes o boro e o manganês não apresentaram variações nas concentrações com o transcorrer da idade das plantas.

As variações mínimas e máximas na concentração desses micronutrientes nos vários órgãos da planta, são apresentadas na Tabela 5. As maiores amplitudes na concentração de boro foram encontradas nas folhas, enquanto para o ferro, manganês e zinco ocorreram nas raízes.

Os resultados analíticos do acúmulo de nitrogênio, fósforo e potássio com base no peso da matéria seca nos diversos órgãos da planta em função da idade, encontram-se na Figura 2A, 2B e 2C. Verifica-se, que todos os macronutrientes aos 240 dias, apresentaram maior acúmulo nas folhas, com exceção do fósforo cujo conteúdo no caule foi igual ao da folha. De acordo com a Figura $2 \mathrm{~A}$, constata-se que o acúmulo de nitrogênio no caule e na raiz até 180 dias, apresentaram pouca variação entre si, porém após esse periodo ocorreu uma maior absorção no caule. $O$ acúmulo total de nitrogênio chegou ao máximo aos 240 dias com um total de $631 \mathrm{mg} / \mathrm{planta}$, sendo $58 \%$ provenientes das folhas. Já o conteúdo total de fósforo nessa mesma época, foi de $126,5 \mathrm{mg} /$ planta.

A Figura $2 \mathrm{C}$, mostra que até 120 dias, a absorçãa do potássio quase não variou. Após essa idade houve um maior acúmulo de potássio nas folhas, chegando a $140 \mathrm{mg} / \mathrm{planta}$ aos 240 dias. Entre o caule e a raiz a variação no acúmulo foi mais evidente após 180 dias. O acúmulo total de potássio foi de 292 $\mathrm{mg} /$ planta.

A figura 3A, mostra que o acúmulo de cálcio aos 60 dias, nos vários órgãos da seringueira, apresentou pouca variação. $O$ total acumulado desse elemento foi de $94,5 \mathrm{mg} / \mathrm{planta}$. O acúmulo de magnésio e enxofre apresentou comportamento semelhante (Figuras 3B e 3C), porém aos 240 dias o conteúdo do enxofre foi um pouco superior ao magnésio, sendo de $65 \mathrm{mg} /$ planta e de $56 \mathrm{mg} / \mathrm{planta}$, respectivamente.

Os maiores conteúdos de macronutrientes nas folhas foram do nitrogênio, vindo na sequência potássio, cálcio, fósforo, enxofre e magnésio. No caule a sequência foi $\mathrm{N}>\mathrm{K}>\mathrm{P}>\mathrm{Ca}>\mathrm{Mg}=\mathrm{S}$, enquanto na raiz foi $\mathrm{N}>\mathrm{K}>\mathrm{P}>\mathrm{S}>\mathrm{Ca}=\mathrm{Mg}$. $\mathrm{O}$ acúmulo total dos macronutrientes na planta inteira em funcão da idade é mostrado na Figura 4.

ALVIM \& MACHADO (1972), estudaram a absorção de macronutrientes em plântulas de seringueira em casa de vegetação, ate 100 dias de idade. Comparando-se os resultados encontrados por estes autores com o do presente trabalho com base nos 120 dias de idade, observa-se valores bem compatíveis, com exceção do nitrogênio (Tabela 6).

O acúmulo dos micronutrientes ferro, manganês, zinco e boro em função da idade é mostrado na figura 5A, 5B e 5C. Com exceção do ferro que apresentou maior absorção nas raízes $(15.727 \mu \mathrm{g} /$ planta $)$ nos demais micronutrientes, o maior acúmulo ocorreu nas folhas. Com relação ao acúmulo de cada micronutriente na folha, constatou-se que a maior absorção aos 240 dias foi do manganês com 1.740,50 $\mu \mathrm{g}$, seguido pelo ferro com $708,75 \mu \mathrm{g}$, zinco com $310,75 \mu \mathrm{g}$ e boro com $308,50 \mathrm{mg} / \mathrm{planta}$. No caule o conteúdo dos micronutrientes obedeceu a seguinte sequência: $\mathrm{Mn}>\mathrm{Fe}>\mathrm{Zn}>\mathrm{B}$, enquanto nas raízes $\mathrm{Fe}>\mathrm{Mn}>\mathrm{Zn}>\mathrm{B}$.

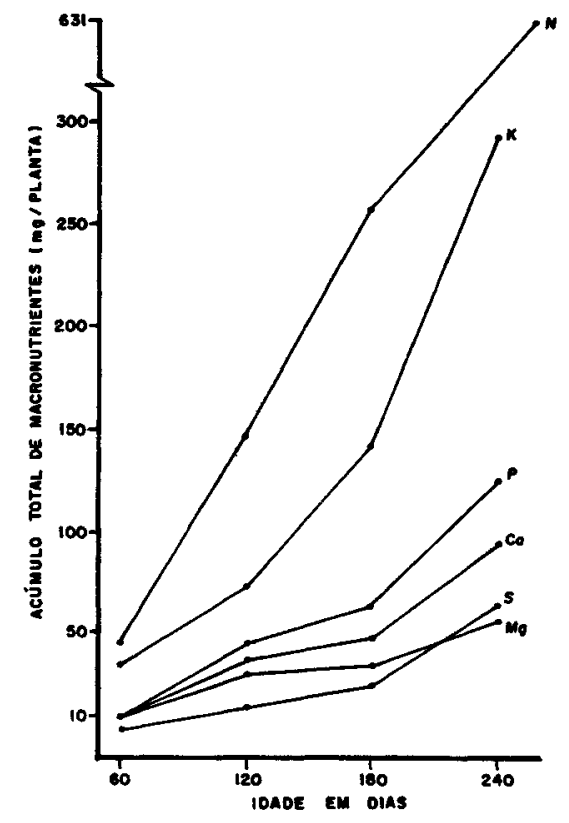

Figura 4 - Acúmulo total de macronutrientes em seringueira em função da idade.

O acúmulo dos micronutrientes na planta inteira aos 240 dias, mostrou que o ferro foi o mais absorvido com $5.727 \mu \mathrm{g} / \mathrm{planta}$, vindo em seguida o manganês com $3.555 \mu \mathrm{g} /$ planta, o zinco com 814 $\mu \mathrm{g}$ /planta e o menos absorvido, o boro, com 479 $\mu \mathrm{g} /$ planta (Figura 6). 


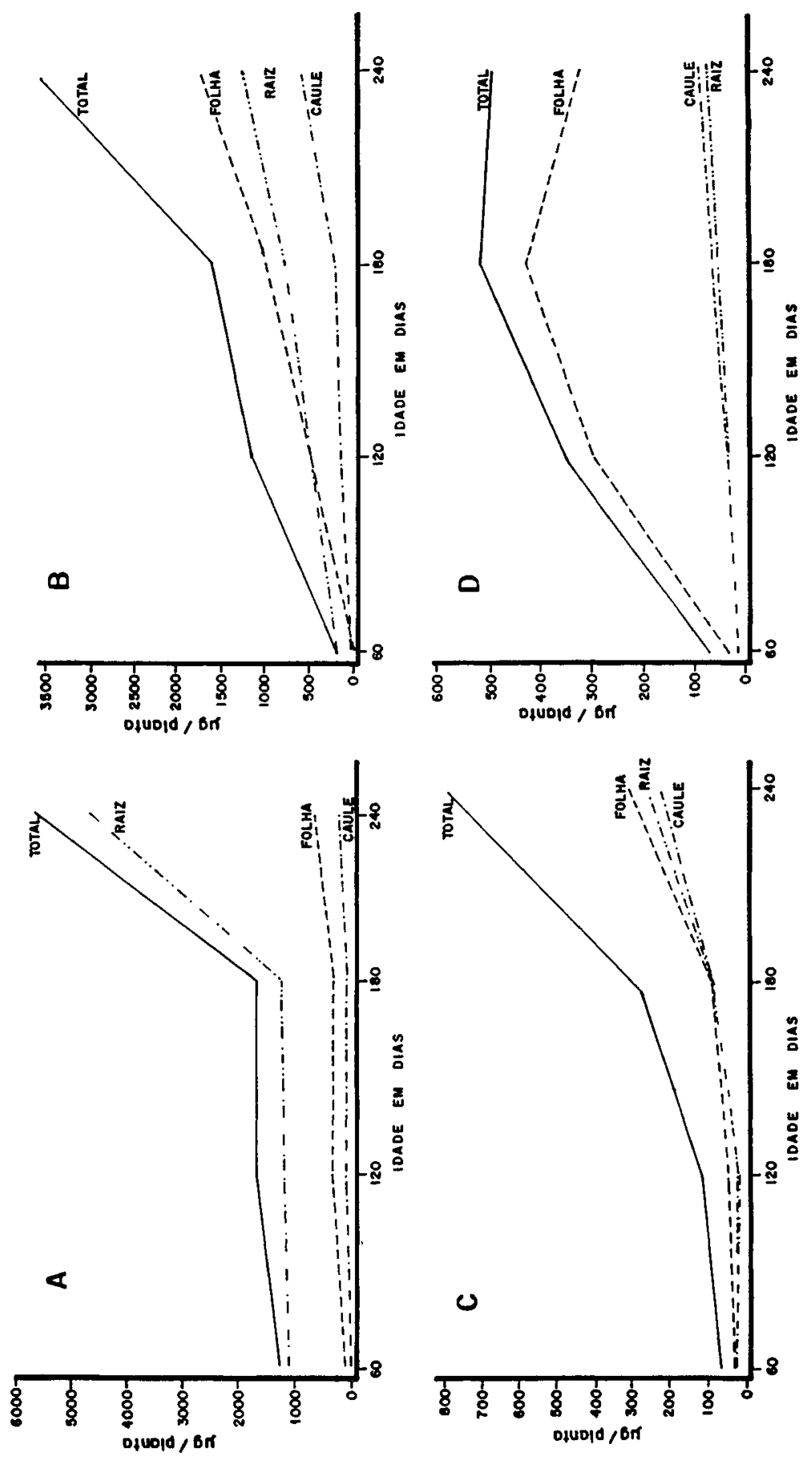

Figura 5 - Acúmulo de ferro (A), manganês (B), zinco (C) e boro (D) nas folhas, caule, raízes e total na seringueira, em função da idade. 
A Tabela 7 , contém as quantidades de nutrientes absorvidos por hectare com base nos resultados obtidos e considerando-se um viveiro com densidade de 95.000 plantas. Inicialmente, a absorção de nutrientes aumentou de 2,8 vezes dos 60 aos 120 dias. Dos 120 aos 180 dias o incremento foi apenas 1,7 vezes e de 2,2 vezes dos 180 a 240 dias.

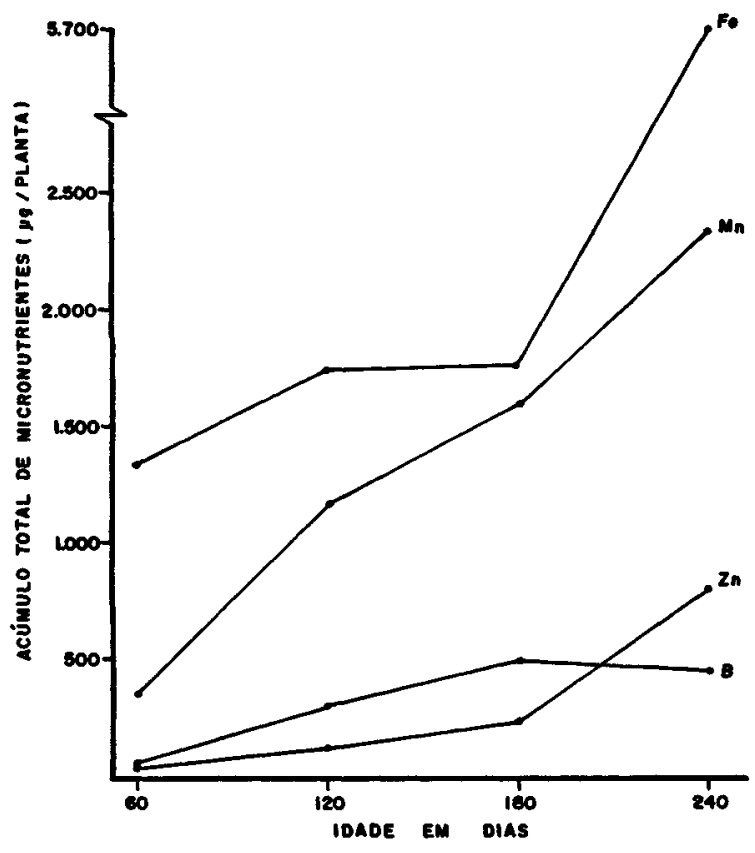

Figura 6 - Acúmulo total de micronutrientes em seringueira em função da idade.

A Tabela 8, apresenta os acréscimos percentuais de nutrientes em função da idade. Os acréscimos percentuais dos 60 a 120 dias foram de $285 \%$ em média. Dos 120 aos 180 dias os acréscimos foram maiores, com aumento de $508 \%$, já dos 180 a 240 dias, os acréscimos foram excepcionais com uma média de cerca de $1.052 \%$. Esse tipo de estudo é importante para se acompanhar a necessidade da adubação. Aos $\mathbf{2 4 0}$ dias, por exemplo, quase todos os nutrientes, com exceção do potássio, boro e ferro, sofreram acréscimos de absorção superior a $1.000 \% \mathrm{em}$ relação aos 60 dias, devendo ser testa uma Epoca de adubação importante para porta-enxertos de seringueira usando evitar problemas futuros de desordens nutricionais.

Dentre os macronutrientes o enxofre foi o elemento que sofreu grande acréscimo percentual de absorção aos 240 dias, com $1.882 \%$. Resultados semelhantes foram obtidos por GUERRINI (1983).

Os modelos das equações de regressão que melhor se ajustaram, com relação ao acúmulo de macro e micronutrientes na planta de seringueira, são apresentados na Tabela 9.

\section{CONCLUSṌES}

1) O periodo mais intenso de crescimento das plantas de seringueira ocorre a partir dos 180 dias.

2) As folhas apresentam, proporcionalmente, uma alta percentagem de matéria seca em relação ao total.

3) As folhas apresentam as maiores concentracões de nutrientes, exceto para o ferro.

4) A quantidade de nutrientes extraídos por hectare, aos 240 dias, $\ell$ :

- Macronutrientes: $60,0 \mathrm{~kg}$ de N, $12 \mathrm{~kg}$ de $P$, $27,74 \mathrm{~kg}$ de $\mathrm{K}, 8,97 \mathrm{~kg}$ de $\mathrm{Ca}, 5,32 \mathrm{~kg}$ de $\mathrm{Mg}$ e $6,21 \mathrm{~kg}$ de S.

- Micronutrientes: $45,52 \mathrm{~g}$ de $\mathrm{B}, 544,08 \mathrm{~g}$ de $\mathrm{Fe}, 337,74 \mathrm{~g}$ de $\mathrm{Mn}$ e 77,30g de $\mathrm{Zn}$.

5) Os acréscimos percentuais de absorção de nutrientes dos 60 dias aos $\mathbf{2 4 0}$ dias de idade, em ordem crescente, foram os seguintes: Fe - 425\%, B - 607\%, $\mathrm{K}-823 \%, \mathrm{Mn}-1.018 \%, \mathrm{Ca}$ e $\mathrm{Mg}-1.055 \%, \mathrm{P}-$ $1.154 \%, \mathrm{Zn}-1.168 \%, \mathrm{~N}-1.330 \%$ e $\mathrm{S}-1.882 \%$.

\section{REFERENCIAS BIBLIOGRÁFICAS}

ALVIM, P. de T. \& MACHADO, A.D. Absorção de minerais e crescimento de cacaueiro e seringueira. In.: Seminário Nacional da Seringueira, 1. Cuiabá, 1972. Anais. Ministério da Indústria e do Comércio, Superintendência da Borracha, Cuiabá, 1972. p. 195-203.

AMARAL, W. do. Deficiências de macronutrientes e de boro em seringueira (Hevea brasiliensis L.D.). Piracicaba,SP. ESALQ/USP. 1983. 44p. Dissertação de Mestrado.

BATAGLIA, O.C. \& CARDOSO, M. Situação nutricional dos seringais de São Paulo. In: Simposio sobre Cultura da Seringueira, 2., Piracicaba, 1987. Anais. Piracicaba, 1987. p.89-97. 
BOLLE-JONES, E. W. Copper, its effects on the growth of the rubber plant (Hevea brasiliensis). Plant and soil, The Hague, 10(2): 150-78, 1957.

BUENO, N. Quantidade de alumínio no substrato afetando o desenvolvimento, a sintomatologia de toxidade, a concentração e o acúmulo de macro e micronutrientes em seringueira (Hevea spp). Piracicaba,SP. ESALQ/USP. 1987. 92p. Tese de Doutorado.

GUERRINI, I.A. Crescimento e recrutamento de macro e micronutrientes no período de quatro anos pela Hevea brasiliensis clone Fx:3864 na regiāo de Rio Branco-AC. Piracicaba,SP. ESALQ/USP. 1983. 105p. Dissertação de Mestrado.

HAAG, H.P.; BUENO, N.; VIÉGAS, I. J.M.; PEREIRA, J.P. Nutrição mineral da seringueira IV. Toxicidade de boro em Hevea brasiliensis. Anais da Escola Superior de Agricultura "Luiz de Queiroz", Piracicaba, 43(1): 219-29, 1986.

HAAG, H.P., DECHEN, A.R., SARRUGE, J.R., GUERRINI, I.A., WERBER, H., TENPRIO, $Z$. Nutriçăo mineral da seringueira - Marcha de absorção de nutrientes. Campinas, Fundação Cargill, 1982. 56p.

MARQUES, R. Efeitos do fósforo e zinco na nutriçāo e crescimento de porta-enxertos de seringueira Hevea brasiliensis spp. Lavras,MG. ESAL. 1990. 110p. Dissertação de Mestrado.

PEREIRA, J. DA PAES. Crescimento de mudas enxertadas de seringueira (Hevea spp) nas condições de sombra e a pleno sol, em função da adubação nitrogenada e potássica, na presenca e ausência da fosfatada e de ácido giberélico, em solo Podzolizado, variação Marilia. Piracicaba,SP, ESALQ/USP. 1989.140p. Tese de Doutorado.

SARRUGE, J.R. \& HAAG, H.P. Análises químicas em plantas. Piracicaba, ESALQ, Departamento de Química, 1974. 56p.
VIÉGAS, I. J.M. Doses de NPK em viveiro de Hevea spp na obtenção de plantas aptas para enxertia em latossolo amarelo textura média na Ilha do Mosqueiro - PA. Piracicaba,SP. ESALQ/USP. 1985. 71p. Dissertação de Mestrado.
Trabalho entregue para publicação em 24.04.91 Trabalho aprovado para publicação em 03.10.91 